Etnográfica

Revista do Centro em Rede de Investigação em

Antropologia

vol. $18(2) \mid 2014$

Vol. $18(2)$

\title{
Das fronteiras como espaço de construção e contestação identitária às questões da segurança
}

on borders as spaces for identity construction and contestation to security issues

\section{Maria de Fátima Amante}

\section{(2) OpenEdition}

Journals

Edição electrónica

URL: https://journals.openedition.org/etnografica/3770

DOI: 10.4000/etnografica.3770

ISSN: 2182-2891

\section{Editora}

Centro em Rede de Investigação em Antropologia

\section{Edição impressa}

Data de publição: 1 junho 2014

Paginação: 415-424

ISSN: 0873-6561

\section{Refêrencia eletrónica}

Maria de Fátima Amante, «Das fronteiras como espaço de construção e contestação identitária às questões da segurança», Etnográfica [Online], vol. 18 (2) | 2014, posto online no dia 09 julho 2014, consultado o 09 fevereiro 2022. URL: http://journals.openedition.org/etnografica/3770 ; DOI: https:// doi.org/10.4000/etnografica.3770

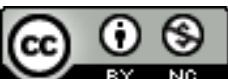

Etnográfica is licensed under a Creative Commons Attribution-NonCommercial 4.0 International License. 


\section{Das fronteiras como espaço de construção e contestação identitária às questões da segurança}

\section{Maria de Fátima Amante}

Nas últimas décadas, as fronteiras internacionais foram sendo objeto da atenção de um número cada vez maior de investigadores das ciências sociais. Daí emergiu uma diversificação dos interesses que reúnem, atualmente, um número consistente de investigadores e onde é possível detetar algumas linhas de pesquisa especializadas, seja nas questões da mobilidade, das identidades de fronteira ou da segurança. O objetivo desta comunicação é o de, a partir da minha experiência de terreno na raia luso-espanhola, apresentar e discutir algumas das orientações de pesquisa no domínio da antropologia das fronteiras.

PALAVRAS-CHAVE: fronteiras, identidade, raia, segurança.

On borders as spaces for identity construction and contestation to security issues - In recent decades, international borders have become the object of attention for a growing number of social sciences researchers. From it, a variety of research interests has emerged, including a significant number of scholars. Today, it is also possible to identity some lines of specialized research, whether in mobility issues, border identities or security. The main goal of this paper is, based on my fieldwork on Portuguese-Spanish borderlands, to present and discuss some current research trends within the domain of the anthropology of borders.

KEYWORDS: borders, identity, raia, security.

AMANTE, Maria de Fátima (mf.amante@iscsp.ulisboa.pt) - CAPP/Unidade Científica de Antropologia, Instituto Superior de Ciências Sociais e Políticas (ISCSP), Portugal. 
NAS ÚLTIMAS DÉCADAS, AS FRONTEIRAS INTERNACIONAIS FORAM SENDO objeto da atenção de um número cada vez maior de investigadores das ciências sociais e humanas. Daí resultou uma diversificação dos interesses que reúne, atualmente, um número consistente de investigadores, de áreas disciplinares muito diversas, e onde é possível detetar algumas linhas de pesquisa mais especializadas, seja nas questões da mobilidade, das identidades de fronteira ou, mais recentemente, da segurança.

O objetivo deste artigo é o de, a partir da minha experiência de terreno na raia luso-espanhola, apresentar algumas das orientações de pesquisa no domínio da antropologia das fronteiras. Trata-se de uma especialização da antropologia política que começou a ter alguma visibilidade na sequência de mudanças políticas ocorridas a partir de início dos anos 90. Os acontecimentos que levaram à alteração do mapa político da Europa tiveram como consequência o surgimento de novas fronteiras internacionais, resultado dos processos de independência no Leste europeu e, paradoxalmente, quase em simultâneo, a "eliminação" de outras fronteiras, algumas de caráter já secular. Refiro-me, claro, aos novos estados resultantes da desagregação da Jugoslávia e da União Soviética, no primeiro caso, e à remoção das fronteiras internas entre os países da União Europeia, no segundo.

Quando em 1998 comecei a interessar-me pela fronteira internacional como um terreno possível para a pesquisa de doutoramento, foi determinante na minha decisão a leitura do número temático de uma revista de informação (que ainda guardo), no qual os jornalistas faziam o percurso ao longo dos mais de 1300 quilómetros de linha de fronteira entre Portugal e Espanha. Era uma reportagem que enfatizava essencialmente o lado turístico de algumas vilas e cidades raianas, com particular destaque para o património natural e arquitetónico, e onde se deixava no ar a ideia de que as pessoas que viviam ao longo da fronteira tinham uma cultura híbrida, onde se misturavam traços identitários e características da cultura portuguesa e espanhola. A decisão prévia de trabalhar questões de identidade, seguindo aquela que era também, desde o final dos anos 80, uma tendência de pesquisa na antropologia do ISCSP, permitiu pensar na possibilidade de trabalhar questões da identidade local, nacional e transnacional, a partir de contextos de partilha, motivados pela proximidade geográfica, social e cultural.

As primeiras explorações da literatura conduziram inevitavelmente a uma produção no âmbito dos border studies, já na altura com alguma dimensão, e a alguns investigadores norte-americanos que, naturalmente, trabalhavam naquele que é, ainda hoje, o maior laboratório dos border studies: a fronteira dos EUA com o México: Oscar Martinez (1994) Pablo Vila (2002, 2003) ou Michael Kearney (1991, 1995). Estas leituras ajudaram a consolidar a decisão de "ir para a raia" mas também foram muito clarificadoras quanto à necessidade de problematizar a identidade na fronteira luso-espanhola de forma 
muito diferente do que estava a ser feito a propósito da fronteira entre os EUA e o México. Ali, a zona de fronteira tinha características muito diferentes das zonas de fronteira na Europa: o fenómeno que mais sobressaía era o intensíssimo movimento de bens e pessoas de sul para norte, muitas em situação irregular, o que fazia com que uma das características mais relevantes fosse a do controlo da fronteira. As cidades de El Paso (Texas) e Ciudad Juarez (Chihuahua, México) e muitas outras ao longo da extensa fronteira entre os EUA e o México são zonas de grande dinamismo económico e populacional, o que significava que a pesquisa etnográfica decorria sobretudo em contexto urbano. No espaço da União Europeia, ao contrário, desde o início dos anos 90 que se insistia num conceito de "Europa das regiões" contra o tradicional conceito de Europa dos Estados-nação. Um elemento-chave na construção política da Europa das regiões havia sido precisamente a "abertura" das fronteiras. $\mathrm{O}$ discurso político do mercado único, primeiro, e da cidadania europeia, depois, apresentava as fronteiras internacionais como anacrónicas, obsoletas e, à luz de uma tendência claramente cosmopolita, desprovidas de sentido. Por isso, na União Europeia, a questão da irregularidade de movimentos, tão central na pesquisa norte-americana, colocava-se mais a propósito das fronteiras externas do que das internas. Por outro lado, contrastava com o dinamismo antes referido um outro padrão, que as distinguia: na Europa, as fronteiras eram, na sua maioria, verdadeiramente periféricas, de fim de território. É este, também, o caso da raia luso-espanhola: na maior parte da sua extensão, a raia é uma zona de características rurais, fracamente povoada, com baixos índices de atividade e elevados índices de dependência, que são, em si, também o resultado de décadas de desinvestimento por parte do poder político central.

O aproveitamento de algum investimento teórico e empírico, embora ainda incipiente, permitiu alguma segurança ao nível do questionamento que me parecia ser adequado ao que a antropologia poderia fazer em torno de um objeto de estudo que, tradicionalmente, pela sua dimensão de inscrição no espaço, foi caro aos geógrafos e, pela sua dimensão política, interessava particularmente os historiadores e os cientistas políticos. Estes investimentos deixavam claro que, embora aproveitando-os, se tornava fundamental encontrar um nicho de interesse mais específico, onde a perspetiva e o método da antropologia pudessem fazer diferença e contribuir, desse modo, para um domínio profundamente eclético, como são os border studies.

\section{ANTROPOLOGIA, FRONTEIRAS E ANTROPOLOGIA DAS FRONTEIRAS}

O conceito de fronteira, e sobretudo o de limite, são conceitos que o antropólogo conheceu e trabalhou, antes de se considerar a pertinência de um domínio dentro da disciplina que se dedicasse especialmente a eles. Importa referir alguns contributos, clássicos, incontornáveis, que são parte de uma investigação 
etnográfica em zonas de fronteira, mas cujos objetivos e interesses estavam ainda distantes do que seria mais tarde concebido como "antropologia das fronteiras". São os casos da experiência de Edmund Leach (1960), em meados do século XX, nas fronteiras da Birmânia, onde se problematizou a noção convencional de fronteira política (barreira, limite, fechamento), contrapondo-lhe a de uma zona na qual as culturas se interpenetravam dinamicamente, através da ação de vários organismos políticos, ecológicos, económicos e de parentesco, pondo em evidência que, embora os conceitos de fronteira, Estado e nação sejam interdependentes, essa relação não funciona sempre da mesma maneira em todos os contextos sociais e políticos. Este trabalho de Leach contraria uma tendência dominante, à época, de se pensar a cultura como núcleo, essência, estudada no centro e não na periferia, nos limites e, por isso, permanece mais isolado dentro daquilo que foram as tendências da antropologia nos anos seguintes.

Muito próxima, no tempo e em conteúdo, está a experiência etnográfica de John Cole e Eric Wolf (1999 [1974]), conduzida em localidades situadas em zonas de fronteira em 1974 e que resultou num estudo que os próprios classificaram como estudo "de ecologia e etnicidade". O trabalho de campo foi conduzido em duas povoações no Norte da Itália (no Tirol italiano), separadas, à data, por um limite provincial, mas que até 1919 haviam estado separadas por uma fronteira internacional. Os autores registam os acontecimentos na vida das duas aldeias e a forma como eram constantemente exibidas, no quotidiano, as diferenças culturais e nacionais por parte dos membros de cada um dos grupos, assim como o recurso fácil aos estereótipos relativos à tradicional situação de separação nacional que antes haviam vivido. Encontramos aqui alguns pontos de contacto com alguma antropologia mais recente, como o trabalho de Daphne Berdhal conduzido em comunidades que haviam estado separadas pelo muro que dividia as "Alemanhas" e onde a estereotipia dependente de uma situação de separação vivida no passado era igualmente acentuada (Berdhal 1999).

$\mathrm{O}$ estudo de Cole e Wolf, que podemos considerar um prelúdio ao que atualmente se convencionou chamar "antropologia das fronteiras" (Donnan e Wilson 1994), de certa maneira, inaugura também uma tendência de pesquisa que será das mais importantes a partir dos anos 90: desmaterialização e persistência, fronteiras materiais e fronteiras mentais, políticas e culturais. Várias pesquisas têm evidenciado que na Europa a "abertura das fronteiras" não quer dizer, necessariamente, desaparecimento de fronteiras, é muito mais uma substituição da fronteira física por fronteiras simbólicas, culturais ou mentais. Esta questão, hoje já datada, de perceber como as pessoas que vivem nas zonas de fronteira avaliam a situação de fronteira aberta e fronteira fechada, viria a constituir parte da problemática de que então me ocupei (Amante 2007).

Em finais dos anos 90, Thomas M. Wilson e Hastings Donnan editam vários livros sobre antropologia, fronteiras e identidade, e referem com insistência a possibilidade de uma área de especialização que seja a "antropologia das 
fronteiras" (Wilson e Donnan 1998; Donnan e Wilson 1999). A proposta dos autores é um domínio de investigação em que se explorem as divergências entre a fronteira política e a fronteira cultural, uma assimetria inevitável entre os discursos do Estado e das populações que vivem nas zonas de fronteira e que fizeram da fronteira um elemento primário de construção da sua identidade: elemento de diferença, mas também, e simultaneamente, um espaço de encontro, de troca e partilha. Era também, como avançavam, a possibilidade de, a partir do estudo do quotidiano das comunidades de fronteira, "pessoas que se sentem habitualmente confortáveis com a ideia de que têm uma ligação cultural com os que vivem em estados vizinhos" (Wilson e Donnan 1998: 4), chegar ao estudo do Estado e do encontro do indivíduo com o Estado. Este foi o questionamento que me levou à raia luso-espanhola.

\section{CONSTRUÇÃO E REPRESENTAÇÃO DA IDENTIDADE NA RAIA LUSO-ESPANHOLA}

A raia luso-espanhola incorpora, numa larga parte da sua extensão, as características sociais, económicas e políticas associadas às periferias. Concebida como um limite histórico-político que é artificial na maior parte do seu traçado, foi o artifício político de que os Estados, português e espanhol, se serviram para a manutenção da diferenciação. Privilegiada a sua conceção de limite, de zona marginal, de "terra de ninguém", foi ficando fora dos planos de desenvolvimento, de investimento, valendo por isso, ainda hoje, o epíteto de "fronteira do subdesenvolvimento" como lhe chamaram Pintado e Barrenechea (1974) nos anos de 1970. Fazer pesquisa de terreno na extensa fronteira luso-espanhola implicou necessariamente uma tomada de decisão quanto à escolha de local e dos lugares. Os critérios que nortearam a escolha do terreno foram vários: queria trabalhar numa zona rural, de pequenas comunidades, várias, portuguesas e espanholas, que teriam de ser "espelhos" umas das outras, para utilizar aqui a expressão de Pais de Brito (1995). Havia à altura vários antropólogos que vinham fazendo trabalho de campo na raia luso-espanhola: Paula Godinho, William Kavanagh, a norte de Portugal e na Galiza, Luís Uriarte e Luís Cunha, na zona da Extremadura espanhola e Alentejo, José Valcuende del Rio em Ayamonte. Acabei por ter a Beira Interior Norte, mais especificamente a zona raiana do conselho do Sabugal, no distrito da Guarda, e a vizinha comarca de Ciudad Rodrigo como terreno, no qual permaneci cerca de 14 meses, entrando e saindo, por diversas vezes. A raia e os fenómenos de mobilidade a ela associados e por ela suscitados - cruzamento diário, práticas de contrabando tradicional, relações sociais transfronteiriças - são elementos estruturantes na construção da identidade local, raiana, e da identidade nacional. Os fronteiriços - ou raianos como se chamam e gostam de ser chamados, identificando-se nesta designação também uma forte consciência de 
individualidade no conjunto nacional - privilegiaram sempre o contacto com a raia e com os que vivem do outro lado. E se o Estado a mantinha fechada, eles insistiam em atravessá-la. Faziam da mobilidade através da raia uma prática quotidiana que não foi menor quando a fronteira estava fechada do que agora que a passagem está liberalizada. A raia e o ato de a atravessar diariamente foram um modo de vida, uma estratégia de luta contra o Estado, uma "arma de fracos" (Scott 1985), legitimada pelas duras condições de vida, agravadas pelo distanciamento que o Estado português, tradicionalmente, interpôs entre si e o interior. As narrativas a que temos tido acesso no terreno são estas em que os raianos se exibem como mais distantes do Estado e mais identificados com a raia; mais distantes dos seus pares nacionais e mais próximos, geográfica, social e culturalmente dos seus vizinhos. Mas o que também percebemos é uma negociação constante da identidade na zona raiana: ao mesmo tempo que se afirmam próximos dos que estão do outro lado, também reafirmam a distância, remetendo para a adscrição nacional, numa valorização inesperada da sua identidade política, em função do anteriormente dito, e numa clara manipulação da sua identidade nacional.

Um aspeto igualmente interessante na conceptualização da fronteira e da identidade local é o seu valor como recurso patrimonial e turístico, enquanto parte do processo de construção e representação identitárias (Amante 2010). A este respeito, avultaram na minha pesquisa a exploração das antigas rotas do contrabando e a sua ativação através da reconfiguração de caminhos antes exclusivamente económicos em caminhos culturais. Igualmente relevante neste processo foi a criação dos museus do contrabando, de que são exemplos o Museu do Contrabando e da Emigração em Melgaço, ou o Museu do Contrabando de Santana de Cambas (Mértola), que, num registo discursivo diferente, cumprem o mesmo objetivo de representação da cultura e identidade das zonas de fronteira e dos que aí vivem ou viveram, numa estratégia claríssima de diferenciação relativamente aos seus pares nacionais. Estes discursos de si são obviamente inseparáveis da fronteira e da sua existência, o que, de uma certa forma, contraria o discurso político que, desde os anos 90, vem enfatizando o desaparecimento da raia luso-espanhola em nome de um novo projeto de relação nas zonas raianas: o da cooperação transfronteiriça. O modo como os raianos conceptualizam a cooperação está distante deste modelo político, europeu: preferem falar da relação social, da amizade de décadas que os liga aos seus vizinhos e da solidariedade que, em momentos específicos, como o da Guerra Civil espanhola, os aproximou ainda mais.

No fundo, a fronteira é objeto de olhares muito diversos e de atribuições de significado igualmente variáveis, em função da experiência que com ela se teve - ou não - no passado, ou que com ela se mantém, no presente. As diferentes conceções e valorizações da fronteira podem ser questionadas através da conceptualização da familiaridade e estranheza que a fronteira 
suscita naqueles que a cruzam diariamente, e que vivem perto dela, os raianos, ou dos que, por viverem mais distantes dela, a cruzam de forma mais esporádica. A familiaridade com a fronteira ou a relação mais distante condiciona diferentemente a decisão de "ir ao outro lado". Tenho explorado esta questão por referência a práticas de consumo e à decisão de passar a fronteira para comprar (Amante 2013a). Isto é particularmente relevante em zonas de fronteira que são verdadeiros espaços comerciais, caso do eixo Elvas-Badajoz, e que, ao longo da segunda metade do século XX se assumiram exatamente dessa forma.

\section{FRONTEIRAS, MOBILIDADE E SEGURANÇA}

O título do artigo deixa perceber a passagem das questões de identidade para as questões de segurança. À medida que a segurança se foi tornando cada vez mais importante para os Estados, quase obsessiva, e estes foram apertando cada vez mais o controlo das fronteiras externas, foi percetível um deslocamento progressivo da atenção dos border studies: das fronteiras internas para as fronteiras externas. Se nos anos 90 a desmaterialização das fronteiras internas europeias era o objeto de estudo mais interessante, a partir do momento em que o 11 de Setembro e os discursos em seu redor criam uma "cultura de medo" e de necessidade de defesa, as fronteiras internacionais voltam a ser o recurso de que os Estados se servem para decidir quem pode, ou não, passar através delas. $\mathrm{Na}$ União Europeia isso traduzir-se-á essencialmente em discursos que enfatizam a importância das fronteiras externas na definição da "Schengenland".

Desde 2005 que o tema da segurança e da intensificação dos processos de securitização tem mobilizado os border studies. Concentrando-se no processo de re-bordering (Van Houtum e Van Naerssen 2002; Van Houtum, Kramsch e Zierhofer 2005; Van Houtum 2010; Rumford 2006), são explorados aspetos como sejam as novas tecnologias de controlo de fronteiras (Pickering e Weber 2006) ou o modo como práticas de re-bordering no espaço Schengen criam regimes de diferenciação entre pessoas e como isso tem impacto nos direitos humanos (Cunningham 2004; Van Houtum e Boedeltje 2009; Goldstein 2010). No fundo, como é que a securitização se impõe verdadeiramente no controlo das fronteiras (Pallitto e Heyman 2008), e como é que as diferentes origens dos que querem atravessar as fronteiras e os motivos por que supostamente o fazem podem ser critérios para impedir a sua entrada no espaço da União Europeia.

As questões de segurança nacional e internacional são um interesse relativamente recente da antropologia, se o comparamos com o seu historial noutras áreas, como a ciência política ou as relações internacionais. A antropologia tem maior investimento, embora igualmente recente, em questões de segurança humana, no modo como as pessoas conseguem criar situações de segurança e nas formas como a segurança económica, política e outras se interrelacionam (Pottier 1999; Eriksen, Bal e Salemink 2010; Donnan e Wilson 2010). 
As fronteiras de Portugal que são fronteiras externas da União Europeia são marítimas e aéreas, e fazem parte dos discursos europeus de securitização. $\mathrm{O}$ meu interesse pelas questões nacionais e igualmente pela forma como o Estado olha, de forma algo descontínua (em termos da importância que lhe atribui), as suas fronteiras, conduziu a minha pesquisa no sentido da exploração da relação entre a fronteira, as agendas políticas internacionais e os discursos em torno da segurança nacional.

A minha experiência neste domínio centrou-se inicialmente na exploração destas questões num quadro de maior excecionalidade, que foi o de serem acontecimentos políticos e os seus protagonistas a definirem a decisão política de fechar o espaço nacional por razões de segurança interna. Em 2010, por ocasião da realização da Cimeira da NATO em Lisboa, pela segunda vez nos últimos 17 anos, o Estado português tomou a decisão de "fechar" o espaço nacional, mantendo bastante apertado o controlo das fronteiras externas e alargando a prática de controlo também à fronteira interna. Durante um curto período de tempo, quatro dias, foi possível observar o modo como as agendas políticas globais condicionaram a mobilidade através das fronteiras e como permitiram que regimes de exceção e de conveniência pudessem ter impacto sobre alguns dos direitos de cidadania europeia. Foi uma ocasião interessante para também perceber o modo como na contemporaneidade, tal como refere Balibar (2004), as fronteiras perdem facilmente a sua condição de periferia, para serem encontradas em locais insuspeitos, como sejam o centro das cidades. Por ocasião da Cimeira da NATO de 2010, o controlo sobre os espaços e as pessoas deslocou-se progressivamente da raia, das fronteiras nos aeroportos e portos marítimos, para o centro da cidade de Lisboa, através do controlo de viaturas que entravam na cidade, que pretendiam aproximar-se das imediações de determinados hotéis onde estavam alojados líderes políticos internacionais que participavam na cimeira e em toda a zona oriental da cidade de Lisboa, particularmente na área circundante do local de realização da cimeira. Para além de revelar a aparente contradição de discursos políticos que rodeiam as fronteiras nacionais (ora são apresentadas como construções anacrónicas, desadequadas ao projeto europeu, espaços de encontro, ideais para o convívio entre povos que tradicionalmente estiveram mais distantes, ora são, de novo, a resposta preferida pelo Estado para lidar com a ansiedade provocada por acontecimentos, grupos ou pessoas), o que a situação de fechamento excecional do espaço nacional revelou, igualmente, foi a extraordinária importância que a segurança tem, para o Estado, e o modo como este tentou, através de práticas mais ou menos ortodoxas (informação, teatralização, ritualização), passar para os cidadãos um sentimento inicial de insegurança, para de seguida, ele próprio, Estado, se assumir como o reduto maior da segurança e da sua garantia (Amante 2013b). 


\section{CONCLUSÃO}

A mais-valia da abordagem antropológica continua a ser o seu olhar de proximidade, causa e consequência da pesquisa etnográfica. Também no que respeita a um objeto de estudo como são as fronteiras internacionais é assim. Continua a ser relevante o significado que as pessoas atribuem às situações, seja à fronteira como elemento de construção identitária, seja como elemento que é capaz de promover sentimentos de segurança, nas pessoas, tomadas individualmente, nas comunidades ou até mesmo no Estado. A antropologia, através da etnografia e do seu enfoque na dimensão cultural e simbólica das fronteiras, tem permitido o acesso aos discursos e narrativas das pessoas sobre as fronteiras e, igualmente, manter um olhar crítico sobre a forma como a fronteira é mantida ou suprimida pelo Estado, em função de condicionalismos de natureza variada.

\section{BIBLIOGRAFIA}

AMANTE, Maria de Fátima, 2007, Fronteira e Identidade: Construção e Representação Identitária na Raia Luso-Espanhola. Lisboa, ISCSP.

AMANTE, Maria de Fátima, 2010, "Local discursive strategies for the cultural construction of the border: the case of the Portuguese-Spanish border", Journal of Borderland Studies, 25 (1): 99-114.

AMANTE, Maria de Fátima, 2013a, "Recovering the paradox of the border: identity and (un)familiarity across the Portuguese-Spanish border", European Planning Studies, 21 (1): 24-43.

AMANTE, Maria de Fátima, 2013b, "State, security, and the media: the ritualization process in contemporary politics", em The Anthology: GODIAC - Good Practice for Dialogue and Communication as Strategic Principles for Policing Political Manifestations in Europe. Uppsala, GODIAC Projektet/Polisens Verksamhetsstöd Informationsenheten, 195-204, disponível em <http://polisen.se/PageFiles/321996/GODIAC_Anthology_2013.pdf> (última consulta em maio de 2014).

BALIBAR, Etienne, 2004, We, the People of Europe: Reflections on Transnational Citizenship. Princeton, NJ, Princeton University Press.

BERDHAL, Daphne, 1999, Where the World Ended: Re-unification and Identity in the German Borderland. Berkeley e Los Angeles, University of California Press.

BRITO, Joaquim Pais de, 1995, Retrato de Aldeia com Espelho: Ensaio sobre Rio de Onor. Lisboa, Publicações Dom Quixote.

COLE, John W., e WOLF, Eric R., 1999 [1974], The Hidden Frontier: Ecology and Ethnicity in an Alpine Valley. Londres e Los Angeles, University of California Press.

CUNNINGHAM, Hillary, 2004, "Nations rebound? Crossing borders in a gated globe", Identities: Global Studies in Culture and Power, 11 (3): 329-350. 
DONNAN, Hastings, e Thomas M. WILSON (orgs.), 1994, Border Approaches: Anthropological Perspectives on Frontiers. Lanham, MD, University Press of America.

DONNAN, Hastings, e Thomas M. WILSON (orgs.), 1999, Borders: Frontiers of Identity, Nation and State. Nova Iorque, Bloomsbury Academic.

DONNAN, Hastings, e Thomas M. WILSON (orgs.), 2010, Borderlands: Ethnographic Approaches to Security, Power and Identity. Lanham, MD, University Press of America.

ERIKSEN, Thomas H., Ellen BAL, e Oscar SALEMINK (orgs.), 2010, A World of Insecurity: Anthropological Perspectives on Human Security. Londres e Nova Iorque, Pluto Press.

GOLDSTEIN, Daniel M., 2010, "Toward a critical anthropology of security”, Current Anthropology, 51 (4): 487-517.

KEARNEY, Michael, 1991, "Borders and boundaries of state and self at the end of empire", Journal of Historical Sociology, 4 (1): 52-74.

KEARNEY, Michael, 1995, "The local and the global: the anthropology of globalization and transnationalism”, Annual Review of Anthropology, 24: 547-565.

LEACH, Edmund, 1960, “The frontiers of Burma”, Comparative Studies in Society and History, 3: 49-68.

MARTINEZ, Oscar J., 1994, Border People: Life and Society in the US-Mexico Borderlands. Tucson, The University of Arizona Press.

PALLITTO, Robert, e Josiah HEYMAN, 2008, “Theorizing cross-border mobility: surveillance, security and identity", Surveillance Studies Network, 5 (3): 315-333, disponível em $<$ http://library.queensu.ca/ojs/index.php/surveillance-and-society/issue/view/Inequality $>$ (última consulta em maio de 2014).

PICKERING, Sharon, e Leanne WEBER, 2006, Borders, Mobility and Technologies of Control. Dordrecht, Springer.

PINTADO, António, e Eduardo BARRENECHEA, 1974, A Raia de Portugal: A Fronteira do Subdesenvolvimento. Madrid, Editorial Cuadernos para el Diálogo.

POTTIER, Johan, 1999, Anthropology of Food: The Social Dynamics of Food Security. Cambridge, Polity Press.

RUMFORD, Chris, 2006, "Introduction: theorizing borders", European Journal of Social Theory, 9 (2): 155-169.

SCOTT, James C., 1985, Weapons of the Weak: Everyday Forms of Peasant Resistance. New Haven, CT, Yale University Press.

VAN HOUTUM, Henk, 2010 , "Human blacklisting: the global apartheid of the EU's external border regime", Environment and Planning D: Society and Space, 28 (6): 957-976.

VAN HOUTUM, Henk, e Freerk BOEDELTJE, 2009, "Europe's shame: death at the borders of the EU", Antipode, 41 (2): 226-230.

VAN HOUTUM, Henk, Olivier KRAMSCH, e Wolfgang ZIERHOFER, 2005, B/ordering Space. Aldershot, Ashgate.

VAN HOUTUM, Henk, e Ton VAN NAERSSEN, 2002, "Bordering, ordering and othering", Tijdschrift voor Economische en Sociale Geografie, 93: 125-136.

VILA, Pablo, 2002, Crossing Borders, Reinforcing Borders: Social Categories, Metaphors and Narrative Identities on the US-Mexico Frontier. Austin, TX, University Press of Texas.

VILA, Pablo, 2003, Ethnography at the Border. Minneapolis, MN, University of Minnesota Press.

WILSON, Thomas M., e Hastings DONNAN, 1998, Borders: Frontiers of Identity, Nation and State. Oxford, Berg. 